\title{
Land Use and Cover Mapping with Airborne Hyperspectral Imager in Setiu, Malaysia
}

\author{
Kamaruzaman Jusoff \\ Tropical Forest Airborne Observatory (TropAIR) \\ Faculty of Forestry, Universiti Putra Malaysia \\ Serdang 43400, selangor, Malaysia \\ Tel: 60-3-8946-7176 E-mail: kjusoff@yahoo.com
}

This research is funded by Global Talent (M) Sdn Bhd. and Universiti Putra Malaysia.

\begin{abstract}
In recent years, land use and land cover plays a pivotal role in global environmental change. Under these circumstances, the need of a new dimension for detecting land use and cover is getting more imperative for conservation and effective management of land use and cover types. Importantly, the use of information technology to support decision making in detecting land use and cover is essential and recent. One of the technologies used is Airborne Remote Sensing. The objective of this study is to identify, quantify, classify and map land use and land cover mapping in Setiu, Terengganu using UPM-APSB's AISA airborne hyperspectral remote sensing. Detection of land use and cover was performed using airborne hyperspectral imaging data taken on 20 April 2006 with the support of existing land use and cover maps. The size of the study area is 100 ha. The image was displayed in ENVI 4.0 Software using bands 202217 (RGB) combination. The data were then enhanced and classified for different land use and cover classes. From the data analysis, the image can be classified into eight classes. The classes are 2-3 years old oil palm plantation, 4-5 years old oil palm plantation, young (3-4 years old) rubber plantation, matured (15-17 years old) rubber plantation, vegetation crops, open area, road and river. The land use and land cover classes area distribution of the plots under study in Setiu, Terengganu were 4.18 ha, 8.58 ha, 6.26 ha, 70.43 ha, 2.98 ha, 2.31 ha, 2.78 ha, and 2.48 ha. Overall, the classification accuracy of interpretation of the airborne imagery for land use and cover in Setiu, Terengganu is 89.51 and kappa coefficient is 0.86 . This study shows that, airborne hyperspectral remote sensing technique is capable in identifying, quantifying, classifying and mapping land use and cover in Setiu, Terengganu, hence a good decision support tool in land use and cover planning and management.
\end{abstract}

Keywords: Landuse, Mapping, Airborne, Hyperspectral, Precision agriculture, Rubber, Oil palm

\section{Introduction}

There are few landscapes remaining on the Earth's surface that have not been significantly altered or are not being altered by humans in some manner. Mankind's presence on the Earth and his modification of the landscape has had a profound effect upon the natural environment. These anthropogenic influences on shifting patterns of land use are a primary component of many current environmental concerns as land use and land cover change is gaining recognition as a key driver of environmental change (Riebsame, et. al., 1994). Changes in land use and land cover are pervasive, increasingly rapid, and can have adverse impacts and implications at local, regional and global scales.

During the past millennium, humans have taken an increasingly large role in the modification of the global environment. With increasing numbers and developing technologies, man has emerged as the major, most powerful, and universal instrument of environmental change in the biosphere today. Both globally, land cover today is altered primarily by direct human use (Meinel and Hennersdorf, 2002). Any conception of global change must include the pervasive influence of human action on land surface conditions and processes.

Viewing the Earth from an aerial view has become essential to comprehend the cumulative influence of human activities on its natural resource base. In a time of rapid, and often unrecorded, land use change, observations from the air provide near real-time objective information of human utilization of the landscape. Airborne hyperspectral remote sensing is providing new tools for advanced ecosystem land use and cover sustainable management. By utilizing 
airborne hyperspectral sensing technologies land use and land cover change of designated areas can be monitored and mapped in near real time for specific research, analysis, quick and precise decision making. Other than that, it is very important for the government to know the status of the land in near real time. Developing methodology for interpreting the land use and land cover with combined with near real-time temporal airborne imageries and cadastre GIS datasets is deemed necessary. Manual (traditional) mapping methods acquire a relatively time-consuming and high expenditure. Pressing needs for land use inventory in many of the developed countries and some of developing countries have already prompted the use of airborne hyperspectral sensing and GIS to provide up-to-date information (Kamaruzaman and Norsuzila, 2008; and Kamaruzaman, 2008a, 2000b, 2000c)

The general objective is to asses the capability and usefulness of UPM-APSB's AISA airborne hyperspectral remote sensing in land use and cover mapping. The specific objective is to identify, quantify, classify and map land use and land cover mapping in Setiu, Terengganu.

\section{Method and materials}

\subsection{Description of study area}

The study was conducted in Setiu, Terengganu within latitude $5^{0} 28^{\prime} 21.91^{\prime \prime}$ to $5^{0} 28^{\prime} 4.07^{\prime \prime}$ North and longitude $102^{0}$ $49^{\prime} 59.82$ to $102^{0} 50^{\prime} 54.58$ East. Figure 1 shows the location of study area in Setiu, Terengganu. Setiu is one of the distinct in Terengganu. Total cover areas in Setiu are 130,436.3 ha. The total plantation areas in Setiu are 36,945.5 ha, including rice paddy, vegetables, fruits, cash crops, coconut, tobacco and others. The mean relative humidity of the study site is about $70 \%$ to $90 \%$. The mean minimum and maximum temperature are $22^{\circ} \mathrm{C}$ to $32^{\circ} \mathrm{C}$ respectively. The annual rainfalls in Setiu fluctuated from the lowest $2990 \mathrm{~mm}$ to the highest of $4003 \mathrm{~mm}$ per year. $90 \%$ of the residents in Setiu are Malay, and the minority races consist of Chinese and Indian.

\section{$<<$ Figure 1. A map of Peninsular Malaysia show in the location of study area in Setiu, Terengganu $>>$}

\subsection{System description}

UPM-APSB's AISA has been proven an accurate and reliable tool for collecting data. UPM-APSB's AISA is a solid-state, push-broom instrument. The small size of the complete system makes it quite portable for use in various aircraft. The instrument can be mounted on a plate that is compatible with a standard aerial camera mount, available in airplanes around the world. Other than that hyperspectral instruments is the flexibility in selecting the sensor's spatial and spectral resolution characteristics. Simple ASCII text configuration files that can be written and loaded at anytime control the sensor settings, bandwidth selections, and integration time. Multiple configuration files are loaded on the controlling computer and used interchangeably throughout the flight depending on the image targets or mission goals.

UPM-APSB's AISA is capable of collecting up to 288 spectral channels within this range, the data rate associated with the short integration times (sampling rates) required of the sensor in most operational/flight modes, limits the number of channels. The full spectral mode, however, is useful for acquiring 288 band spectral signatures of specific targets that can be used to generate pure end members as well as for band selection purposes. Current operational collection configurations range from 10 to 70 spectral bands depending on the aircraft speed, altitude and mission goals. The placement of the spectral bands is completely configurable and the user selected bandwidths can range anywhere from $\sim 2 \mathrm{~nm}$ to $\sim 10 \mathrm{~nm}$.

\subsection{Data acquisition and image processing}

The raw data pre-processed image (Figure 2) has been analysed from the UPM-APSB's AISA airborne hyperspectral remote sensing on-board the aircraft. The image was used for land use and land cover classification. The data which is in digital format was obtained from UPM- Aeroscan Precision (M) Sdn Bhd.

\section{<<Figure 2. A raw data image from the UPM-APSB's AISA airborne hyperspectral sensor >>}

The image processing and analysis was done by a personal computer using The Environment for Visualizing Images (ENVI) 4.0 system. Data collection, analysis and ground verification are the three main components involved in this study. Manual classification involved visual observation based on differences in the spectral responses and image contrast. There are 20 bands used in the data analysis. A selection of band combination of the image was attempted in order to acquire the appreciate False Colour Composite Image (FCC) of the study.

For this study, 30 sampling point were selected randomly during the ground verification. Photographs were taken and parameters related to land use and land cover types to this study were recorded. All collected data obtained from ground verification were used to determine the accuracy of mapping. Accuracy assessment needs to ensure that the classification has been done was precise as to the real condition on the ground. Mapping accuracy was made through an error matrix. The pixel that has been categorized from the image was compared to the same site in the field. If the comparison is match, it would be put under similar category. The original references data were obtained from ground visits and topographic map. The reference data was simply done by calculating the percentage of the truly classified 
pixels over total number of pixels that were presented in the confusion matrix. Meanwhile, the mean classification accuracy was calculated as the function of total training pixel against the total correct pixel over the total pixel.

\section{Results and discussions}

In this study, Bands 1-29 of airborne hyperspectral imaging were tested for selection of suitable band combination to get a good colour combination image that can give more information about land use and land cover. Image represented by band 20,22 and 17 showed the best quality among all the airborne hyperspectral imaging bands. From the colour enhancement technique, agricultural area, open area, and road are easily recognized because of their dark colour against the light background of rubber plantation and oil palm plantation. Combination of bands 20, 22 and 17 (RGB) showed excellent result in identifying and differentiating land use and land cover pattern. Figure 3 showed the colour enhanced image which is much easier to recognize because the increasing of information for visually interpreted from the image.

\section{$<<$ Figure 3: Airborne hyperspectral image after enhancement showing land use and cover of Setiu,} Terengganu $>>$

In this study, the enhanced image was classified using a SAM supervised classification. A total of eight different classes of land use and cover types were able to be classified and mapped as follows: Class 1: Oil palm plantation (2-3 Years), Class 2: Oil palm plantation (4-5 Years), Class 3: Young Rubber plantation (3-4 Years), Class 4: Matured Rubber Plantation (15-17 Years), Class 5: Agricultural crops (bananas, rubber saplings (1 year) and pumpkin), Class 6: Open area, Class 7: Road and Class 8: River. The result of the eight classes of land use and cover and the reflectance of spectral signature for this classification is shown in Figures 4-11.

\section{$<<$ Figure 4. Image and spectral signature for $2-3$ years old oil palm plantation}

\section{Figure 5. Image and spectral signature for $4-5$ years old oil palm plantation}

Figure 6. Image and spectral signature for young (3-4 years old) rubber plantation

Figure 7. Image and spectral signature for matured (15-17 years old) rubber plantation

Figure 8. Image and spectral signature for agricultural crops (bananas, 1 year old

rubber plantation(1years) and pumpkin)

Figure 9. Image and spectral signature for open area

Figure10. Image and spectral signature for road

\section{Figure 11. Image and spectral signature for river $>>$}

Based on the image and spectral signature in Figures 4-11, it can be seen that every class of land use and cover have their own reflectance of spectral signature. The difference in reflectance of spectral signature can be used to classify the land use and land cover. Agricultural crops classes have higher reflectance of spectral signature. This is perhaps due to the lower absorption of light compared to other land use and cover types. The nutritional deficiency in the vegetation usually decreases absorption and increase reflectance and transmittance in the visible wavelength. So, the increasing of nutritional in agricultural crops gives higher reflectance of the spectral signature. On the other hand, the study by Ourcival (1999) found that development factor such as leaf age and plant species are also can caused dissimilar reflectance spectra. Besides, the reflectance of spectral signature for young (3-4 years old) rubber plantation are higher compared to matured (15-17 years old) rubber plantation. The decrease of chlorophyll concentration is a factor that effects this situation. The low level of chlorophyll should be due to the normal ageing process. Iron, magnesium, nitrogen and sunlight are necessary for chlorophyll production, so lack of any one of these can lead to yellowing of leaves (Kupiec and Curran, 1993) and provided the decreasing reflectance in spectral signature. Open area, river and road classes have low reflectance of spectral signature. The decrease of open area spectral reflection is depending on organic content, moisture contents and various other minerals. For example, as soil becomes moist, its reflectance decreases. Thus, river and road is strong absorber of reflectance energy in the infrared portion of the electromagnetic spectrum. The reflectance of river and road is generally low. The field photographs taken for each landuse and cover during ground verification is illustrated in Figures 12-17.

$<<$ Figure 12. Ground photos for a young (L) and matured (R) oil palm plantations $>>$

$<<$ Figure 13. Ground photos for a young (L) and matured (R) rubber plantations $>>$

$<<$ Figure 14. Ground photos for a mixed agriculture (L) and an open area (R)>>

$<<$ Figure 15. Ground photos for a road $(L)$ and a small muddy river $(R)>>$

Table 1 showed the total amount of land use and land cover classes of the study area in Setiu, Terengganu. The image point out that, they were eight land use and land cover classes. The classes were 2-3 years old oil palm plantation, 4-5 years old oil palm plantation, young (3-4 years old) rubber plantation, matured (15-17 years old )rubber plantation, agricultural crops, open area, road and river The total area and percentage of every land use and land cover are counted 
according to the total pixels for each class by using the software. The major land use and land cover classes area distribution of Setiu, Terengganu were 2-3 years old oil palm plantation $(4.18 \%)$, 4-5 years old oil palm plantation (8.58\%), young (3-4 years old) rubber plantation (6.26\%), matured (15-17 years old) rubber plantation (70.43\%), agricultural crops $(2.98 \%)$, open area $(2.31 \%)$, road $(2.78 \%)$, and river $(2.48)$.

\section{$<<$ Table 1. Land use and cover classes of the study area in Setiu, Terengganu>>}

The result was assessed for accuracy after completing the classification procedure. The results for accuracy assessment were shown in the Table 2 using confusion matrix. The overall accuracy was $89.51 \%$ which is higher than qualification accuracy of a digital classified image of $80 \%$. Kappa coefficient was 0.86 . Kappa analysis is discrete multivariate technique of use in accuracy assessment (Congalton and Mead, 1983). Table 3 shown the producer's and user's of classification.

\section{$<<$ Table 2. Confusion matrix of the image classification for the study area $>>$ \\ $<<$ Table 3. Producer's and user's accuracy of the image classification for study area $>>$}

Table 3 showed that the highest producer's accuracy was road which achieved 97.78\%. Others classes were in the average of $85 \%$, such as $2-3$ years old oil palm plantation (95.60\%), 4-5 years old oil palm plantation (87.64), young(3-4 years old) rubber plantation (84.18\%), matured (15-17 years old ) rubber plantation, agricultural crops $(95.55 \%)$ and river $(94.95 \%)$. The lowest producer's accuracy was the open area $(97.78 \%)$. Road class hit the highest user's accuracy of $97.78 \%$. Road were easier to be identified due to the highest reflection than the surrounding rubber plantation, oil palm plantation and agricultural crops. The open area class had the lowest accuracy of $72.49 \%$ due to misclassification of agricultural crops during image classification. The user's accuracy of 2-3 years old oil palm plantation, 4-5 years old oil palm plantation, young (3-4 years old) rubber plantation, matured (15-17 years old ) rubber plantation, agricultural crops, open area, road and river were $89.31 \%, 89.31 \%, 78.78 \%, 97.72 \%, 81.12 \%, 92.62 \%$, $74.87 \%$, and $90.30 \%$.

\section{Conclusion}

It can be concluded that the UPM-APSB's AISA is capable and useful for detecting, identifying, quantifying classifying and mapping land use and land classes with an overall accuracy was $89.51 \%$ and Kappa coefficient was 0.86 . The 100 ha size study area of Setiu comprise of land use and cover with 2-3 and 4-5 years old oil palm plantation, a 3-4 (young) and 15-17 (matured) years old rubber plantation, mixed agricultural crops, open areas, roads and rivers. It is quite evident from this study that the most of villagers planted rubber for their income with an areal extent of 70.43 ha for matured rubber and 6.26 ha for young rubber followed by oil palm (4.18 ha for 3-4 years old and 8.58 ha for 15-17 years old), 2.98 ha for mixed agricultural crops, 2.31 ha for open areas, 2.78 ha for roads and 2.48 ha for rivers.

Airborne hyperspectral sensing is a potential tool for monitoring and estimating agricultural land use and cover because it can provide quicker information than traditional mapping method. Development should attempt to operationalize airborne hyperspectral sensing intensively for future planning and control of the sustainable agricultural land use and land cover development in Setiu, Trengganu, Malaysia.

\section{References}

Kamaruzaman Jusoff. (1993). Remote Sensing Application for Forest Land Use Planning. Paper Prepared for Symposium Sumber Alam Tropika, 6-11 December 1993, Universiti Malaysia Sarawak, Kuching, Malaysia. 25p.

Kamaruzaman Jusoff and Norsuzila Ya'acob. (2008). Mapping of Power Transmission Lines on Malaysian Highways using UPM-APSB's AISA Airborne Hyperspectral Imaging System. Journal of Computer \& Information Science. Canadian Center of Science \& Education, (CCSE), Canada. Issue of Vol. 1, No.1, February 2008:88-94.

Kamaruzaman Jusoff. (2008a). Geospatial Information Technology for Conservation of Coastal Forest and Mangroves Environment in Malaysia. Journal of Computer \& Information Science. Canadian Center of Science \& Education, (CCSE), Canada. Issue of Vol.1, No.2. May 2008: 129-134.

Kamaruzaman Jusoff and Hj. Malek Mohd Yusoff. (2008). Airborne Hyperspectral Imagery for Agricultural Businesses in Malaysia. Journal of International Business Research. Canadian Center of Science \& Education, (CCSE), Canada. The Issue of Vol. 1, No.3, July 2008: 54-62.

Kamaruzaman Jusoff. (2008b). Search-and-Rescue (SAR) Operations for the Missing Bell 206 Long Ranger Helicopter in Sarawak, Malaysia using Near Real-Time Airborne Hyperspectral Imaging Systems. Disaster Prevention \& Management: An International Journal, U.K. ISSN: 0965-3562. Emerald Group Publishing Limited, UK. Vol. 17: Issue: 1. pp: 94-103.

Kamaruzaman Jusoff. (2008c). Development of Geographic Information System Database for Town Planning of Sri Serdang, Malaysia using UPM-APSB's AISA Airborne Hyperspectral Imaging Data. The National Mapping \& Spatial 
Data Committee (JPDSN). (2008). Malaysian National Survey \& Mapping Department. Bulletin GIS. ISSN $1394-5505$. July 2008. No.1/2008 pp:1-22.

Kupiec, J.and Curran, P. J. (1993). AVIRIS Spectral Correlated with the Chlorophyll Concentration of Forest Canopy. Summaries of the Fourth Annual JPL Airborne Geoscience Workshop, 1: 105-18 pp.

Meinel, G. and Hennersdorf. J. (2002). Classification Systems of land cover land use and their challenges for picture processing of remote sensing data - Status of international discussion and programs, in Proceeding of the $3^{\text {rd }}$ International Symposium Remote Sensignof Urban Areas 11- 13.06.2002, Istanbul : $472-479$ pp.

Ourcival, J. M., R. Joffre and S. Rambal. (1999). Exploring the Relationship Between Reflectance and Anatomical and Biochemical Properties in Querces ilex leaves. New Phytol. 143: 351-364.

Riebsame, W.E., Parton, W.J., Galvin, K.A., et, al. (1994). May 01. Integrated modeling of land use and cover change.

Table 1. Land use and cover classes of the study area in Setiu, Terengganu

\begin{tabular}{|l|l|l|}
\hline Class & Area (Hectares) & Percentage( \% ) \\
\hline 2-3 years old oil palm plantation & 4.18 & 4.18 \\
\hline 4-5 years old oil palm plantation & 8.58 & 8.58 \\
\hline Young (3-4 years old) rubber plantation & 6.26 & 6.26 \\
\hline Matured (15-17 years old) rubber plantation & 70.43 & 70.43 \\
\hline Agricultural crops & 2.98 & 2.98 \\
\hline Open area & 2.31 & 2.31 \\
\hline Road & 2.78 & 2.78 \\
\hline River & 2.48 & 2.48 \\
\hline TOTAL & 100.00 & 100.00 \\
\hline
\end{tabular}


Table 2. Confusion matrix of the image classification for the study area

\begin{tabular}{|l|l|l|l|l|l|l|l|l|l|}
\hline \multicolumn{7}{|c|}{$\begin{array}{l}\text { Overall accuracy }=(16294 / 18203) 89.51 \% \\
\text { Kappa Coefficient }=0.86\end{array}$} \\
\hline \multicolumn{7}{|c|}{ Ground Truth Pixels } \\
\hline CLASS & A & B & C & D & E & F & G & H & TOTAL \\
\hline A & $\mathbf{1 1 9 5}$ & 82 & 0 & 53 & 0 & 0 & 0 & 8 & 1338 \\
\hline B & 0 & $\mathbf{1 5 2 5}$ & 0 & 380 & 0 & 0 & 0 & 2 & 1907 \\
\hline C & 7 & 4 & $\mathbf{1 2 4 0}$ & 292 & 0 & 11 & 8 & 12 & 1574 \\
\hline D & 40 & 119 & 8 & $\mathbf{7 5 2 9}$ & 0 & 0 & 0 & 9 & 7705 \\
\hline E & 0 & 0 & 137 & 0 & $\mathbf{9 6 7}$ & 77 & 0 & 11 & 1192 \\
\hline F & 0 & 0 & 15 & 1 & 13 & $\mathbf{9 0 4}$ & 18 & 25 & 976 \\
\hline G & 0 & 1 & 47 & 33 & 31 & 245 & $\mathbf{1 1 4 7}$ & 28 & 1532 \\
\hline H & 8 & 9 & 26 & 138 & 1 & 10 & 0 & $\mathbf{1 7 8 7}$ & 1979 \\
\hline TOTAL & 1250 & 1740 & 1473 & 8426 & 1012 & 1247 & 1173 & 1882 & $\mathbf{1 8 2 0 3}$ \\
\hline
\end{tabular}
$\mathrm{A}=$ Young oil palm plantation
$\mathrm{E}=$ Agricultural crops
$\mathrm{B}=$ Matured oil palm plantation
$\mathrm{F}=$ Open area
$\mathrm{C}=$ Young rubber plantation
$\mathrm{G}=\operatorname{Road}$
$\mathrm{D}=$ Matured rubber plantation
$\mathrm{H}=\mathrm{River}$

Table 3. Producer's and user's accuracy of the image classification for study area

\begin{tabular}{|l|c|c|c|c|}
\hline \multirow{2}{*}{\multicolumn{1}{|c|}{ Classes }} & \multicolumn{2}{|c|}{ Producer's Accuracy } & \multicolumn{2}{c|}{ User's Accuracy } \\
\cline { 2 - 5 } & Pixel & $\begin{array}{c}\text { Percentage } \\
(\%)\end{array}$ & Pixel & $\begin{array}{c}\text { Percentage } \\
(\%)\end{array}$ \\
\hline $\begin{array}{l}\text { 2-3 years old } \\
\text { oil palm plantation }\end{array}$ & $1195 / 1250$ & 95.60 & $1195 / 1338$ & 89.31 \\
\hline $\begin{array}{l}\text { 4-5 years old } \\
\text { oil palm plantation }\end{array}$ & $1525 / 1740$ & 87.64 & $1525 / 1907$ & 89.31 \\
\hline $\begin{array}{l}\text { Young (3-4 years old) } \\
\text { rubber plantation }\end{array}$ & $1240 / 1473$ & 84.18 & $1240 / 1574$ & 78.78 \\
\hline $\begin{array}{l}\text { Matured (15-17 years old) } \\
\text { rubber plantation }\end{array}$ & $7529 / 8426$ & 89.35 & $7529 / 7705$ & 97.72 \\
\hline Agricultural crops & $967 / 1012$ & 95.55 & $967 / 1192$ & 81.12 \\
\hline Open area & $904 / 1247$ & 72.49 & $904 / 976$ & 92.62 \\
\hline Road & $1147 / 1173$ & 97.78 & $1147 / 1532$ & 74.87 \\
\hline River & $1787 / 1882$ & 94.95 & $1787 / 1979$ & 90.30 \\
\hline
\end{tabular}




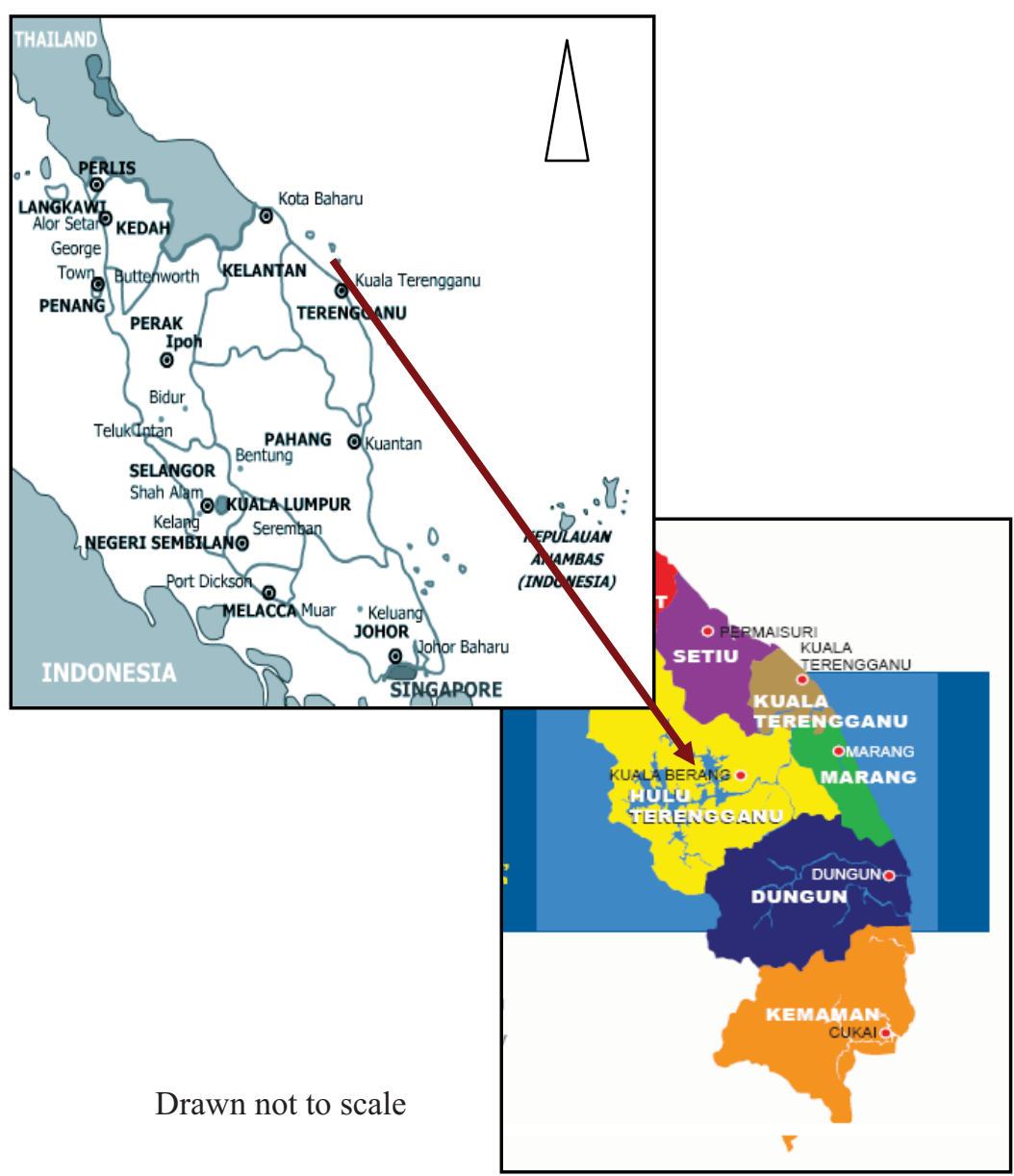

Figure 1. A map of Peninsular Malaysia show in the location of study area in Setiu, Terengganu

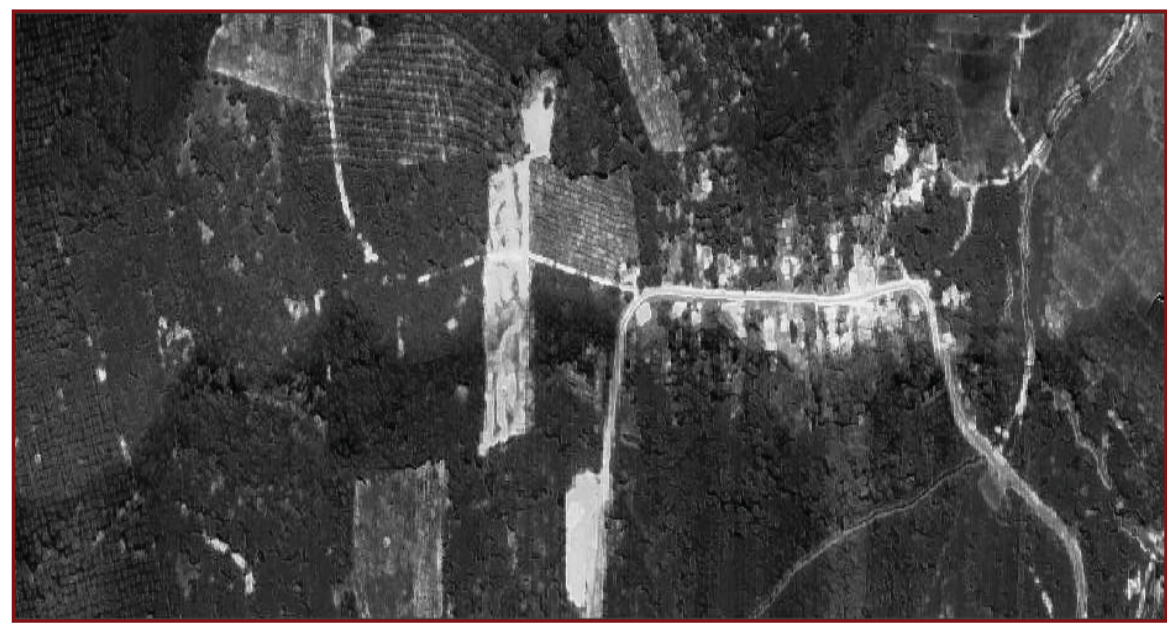

Figure 2. A raw data image from the UPM-APSB's AISA airborne hyperspectral sensor 


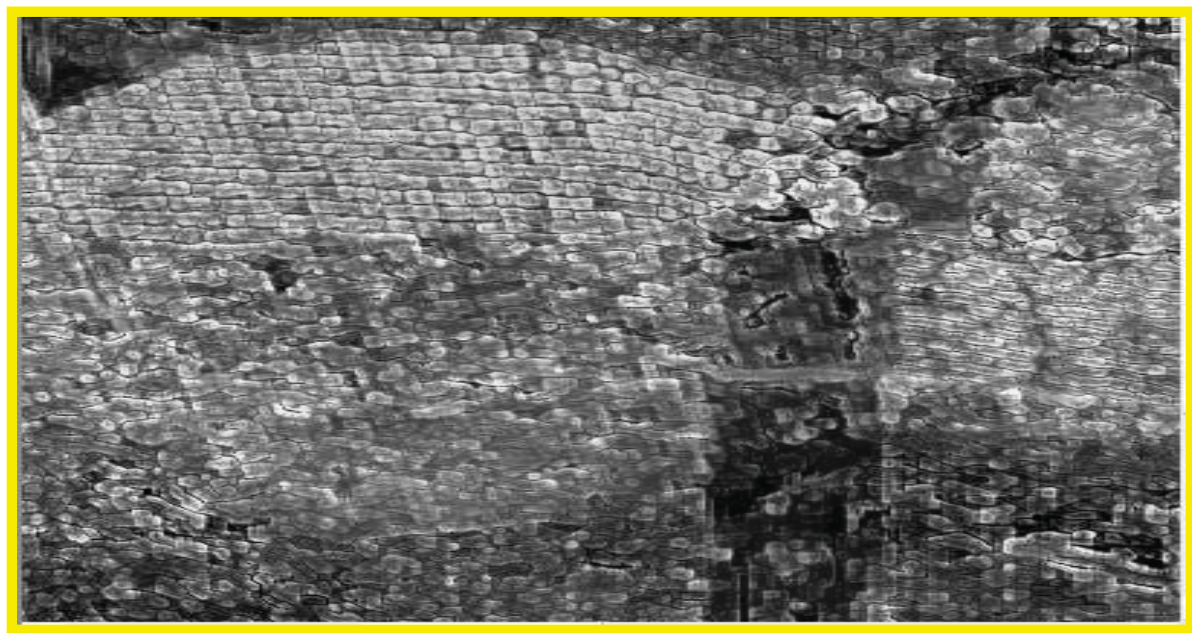

Figure 3. Airborne hyperspectral image after enhancement showing land use and cover of Setiu, Terengganu
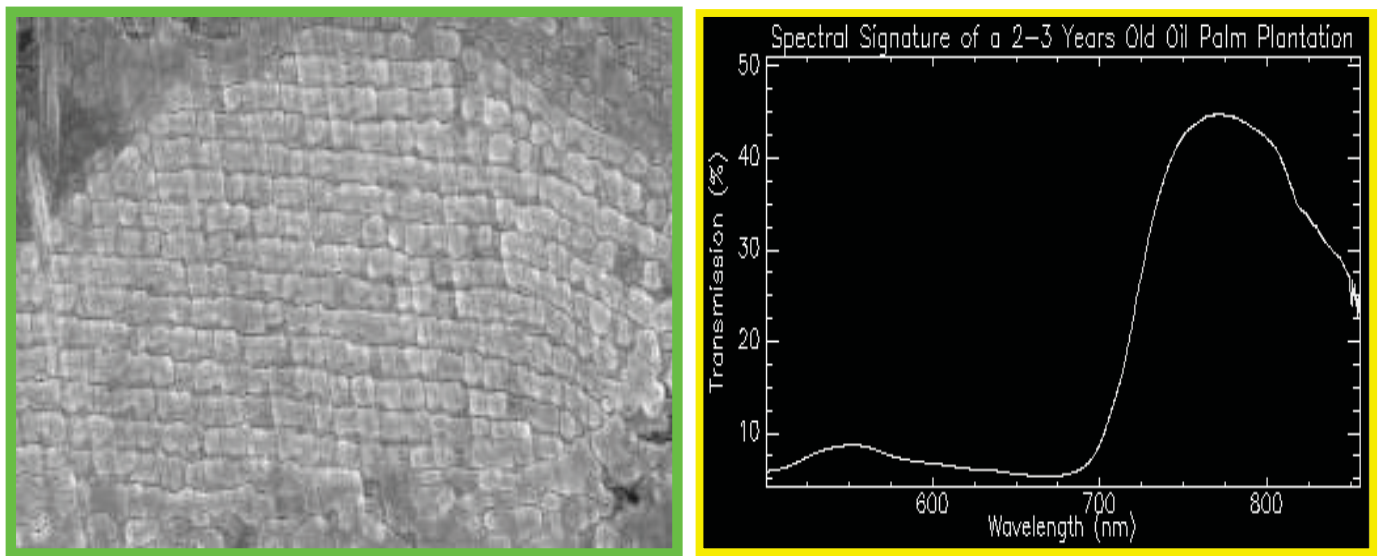

Figure 4. Image and spectral signature for $2-3$ years old oil palm plantation
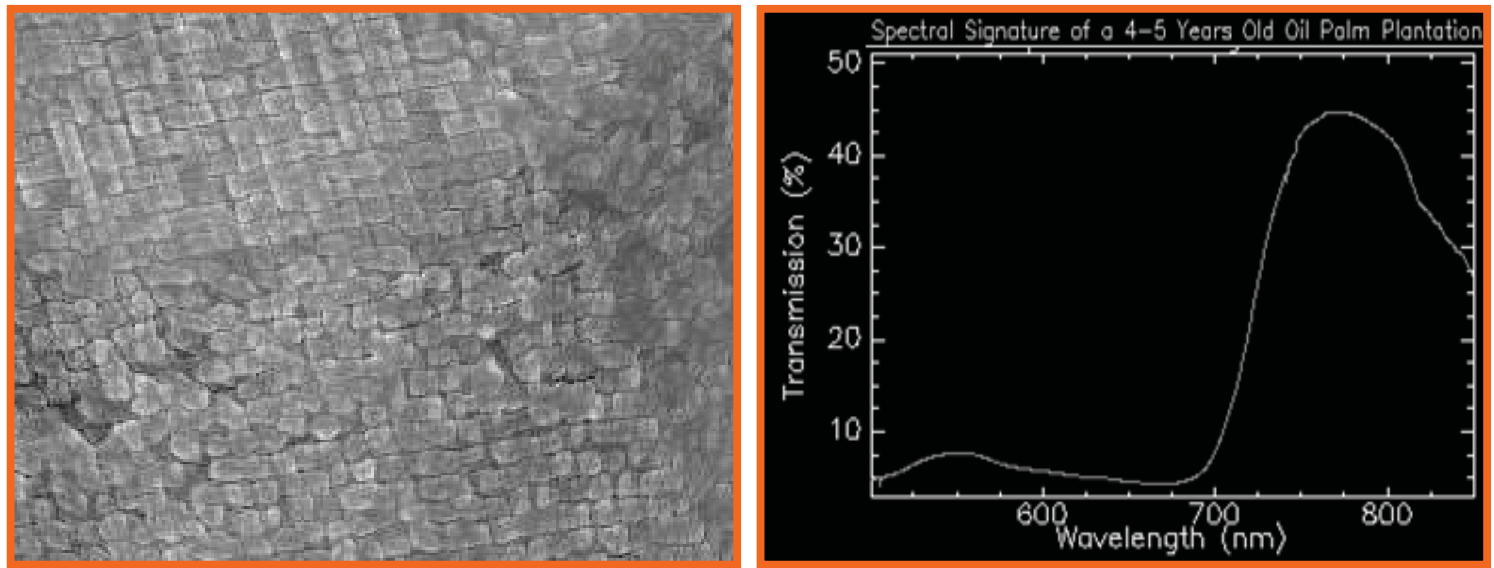

Figure 5. Image and spectral signature for $4-5$ years old oil palm plantation 

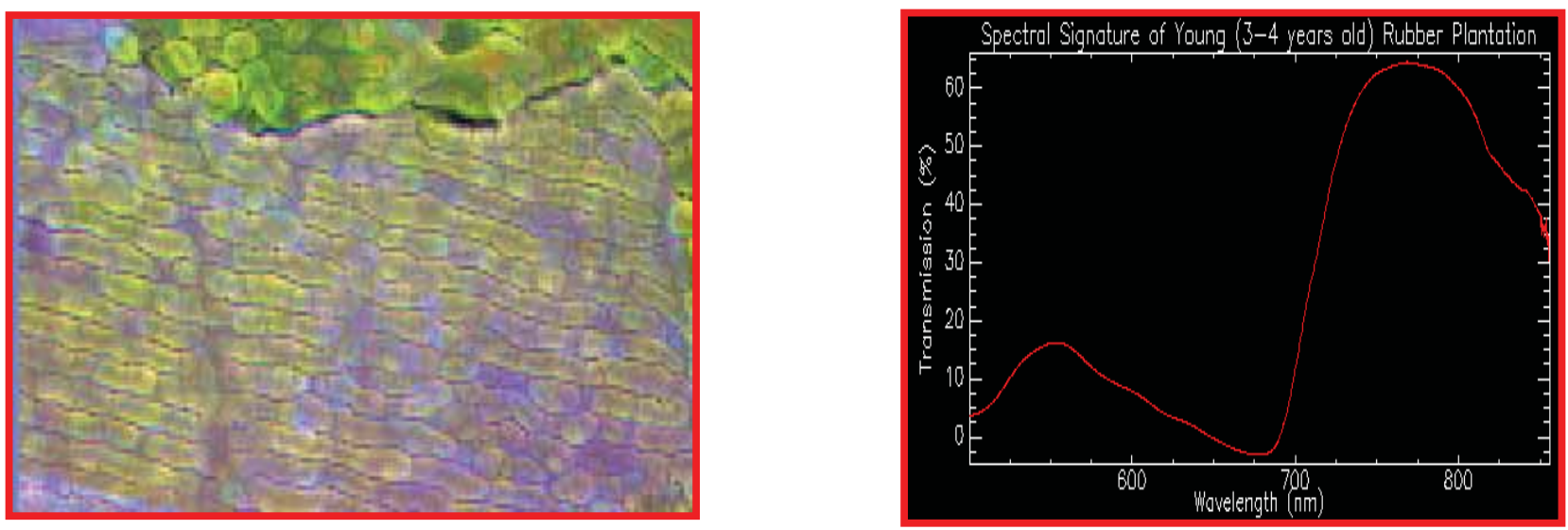

Figure 6. Image and spectral signature for young (3-4 years old) rubber plantation
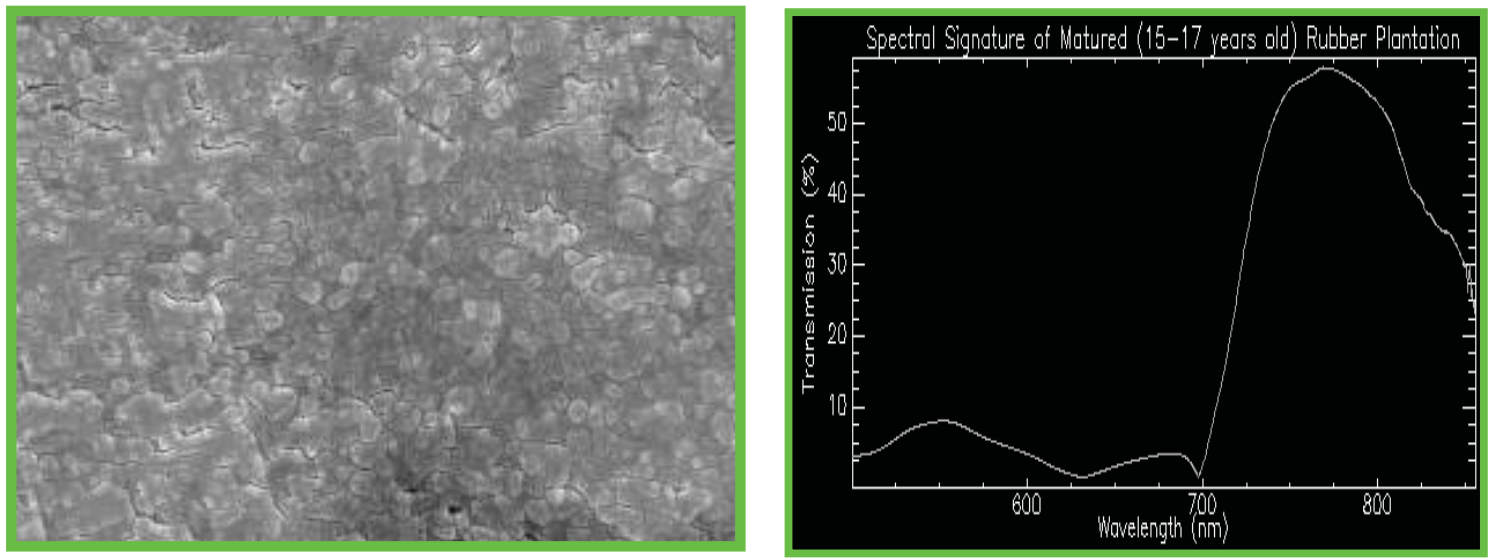

Figure 7. Image and spectral signature for matured (15-17 years old) rubber plantation
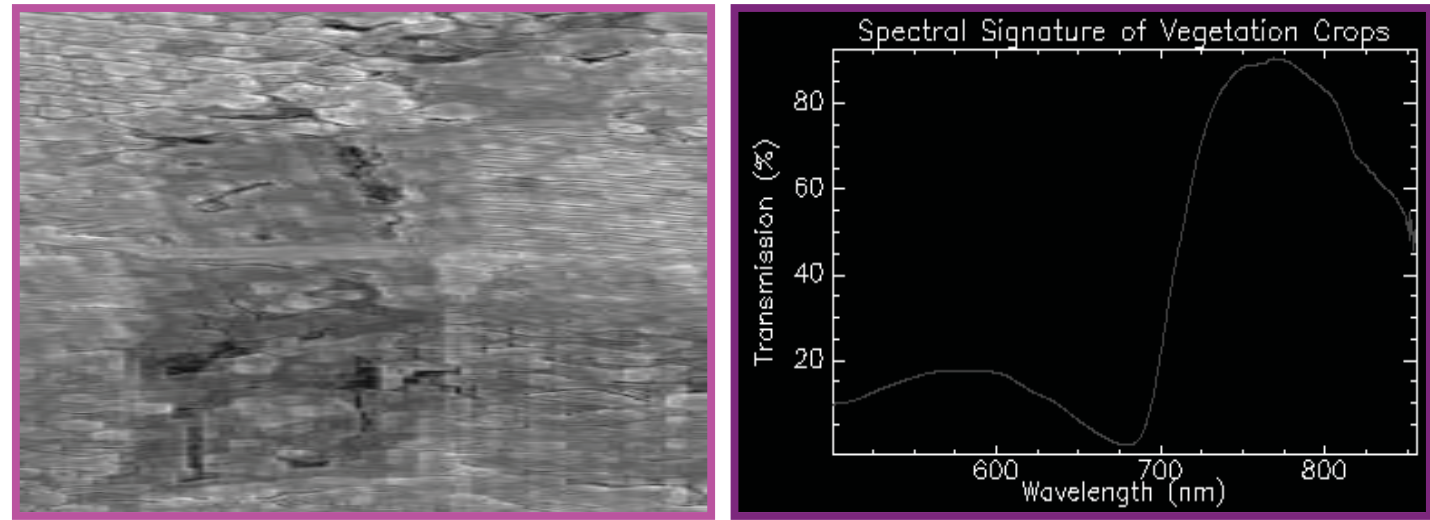

Figure 8. Image and spectral signature for agricultural crops (bananas, 1 year old rubber plantation and pumpkin) 

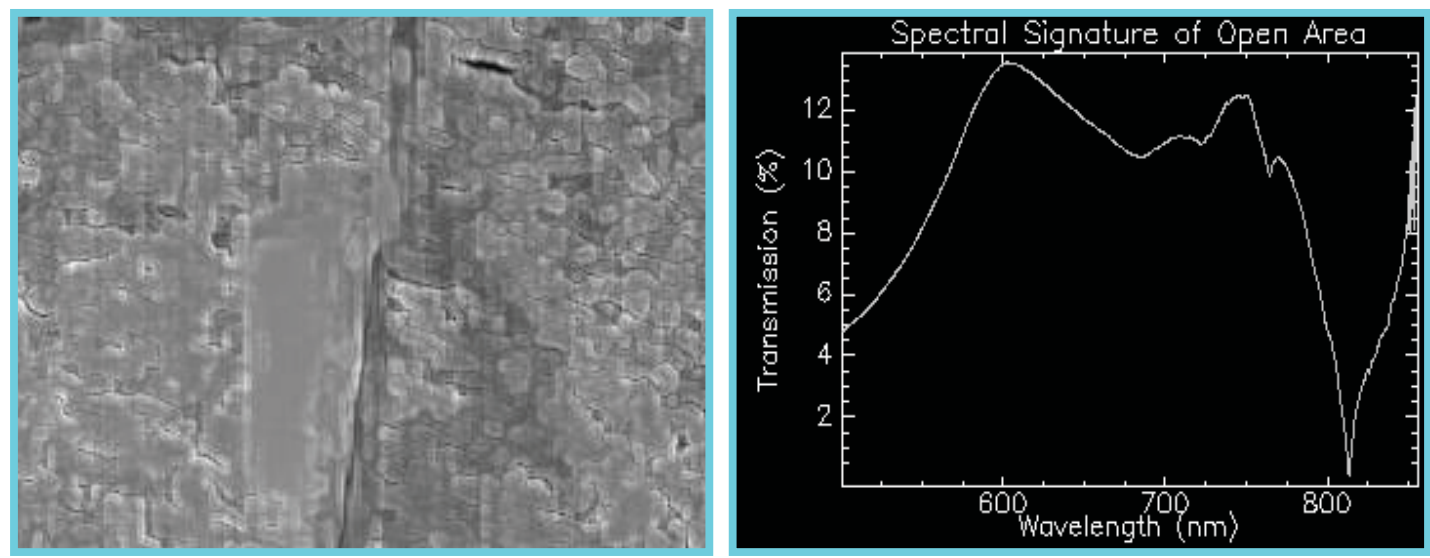

Figure 9. Image and spectral signature for open area
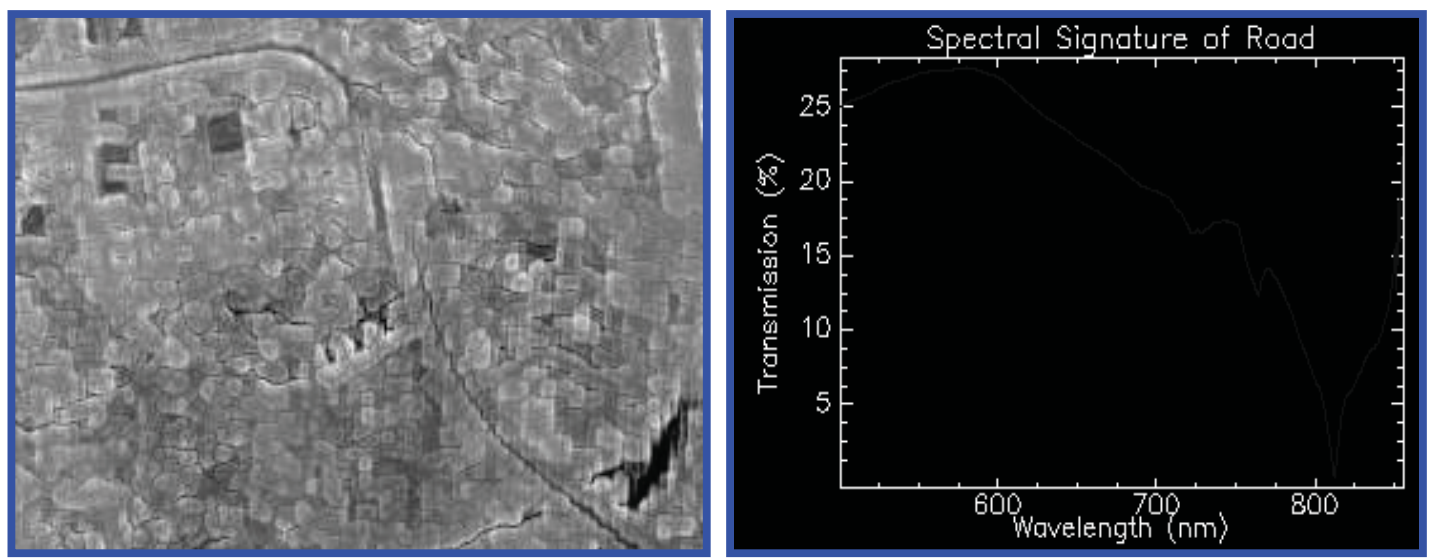

Figure 10. Image and spectral signature for road
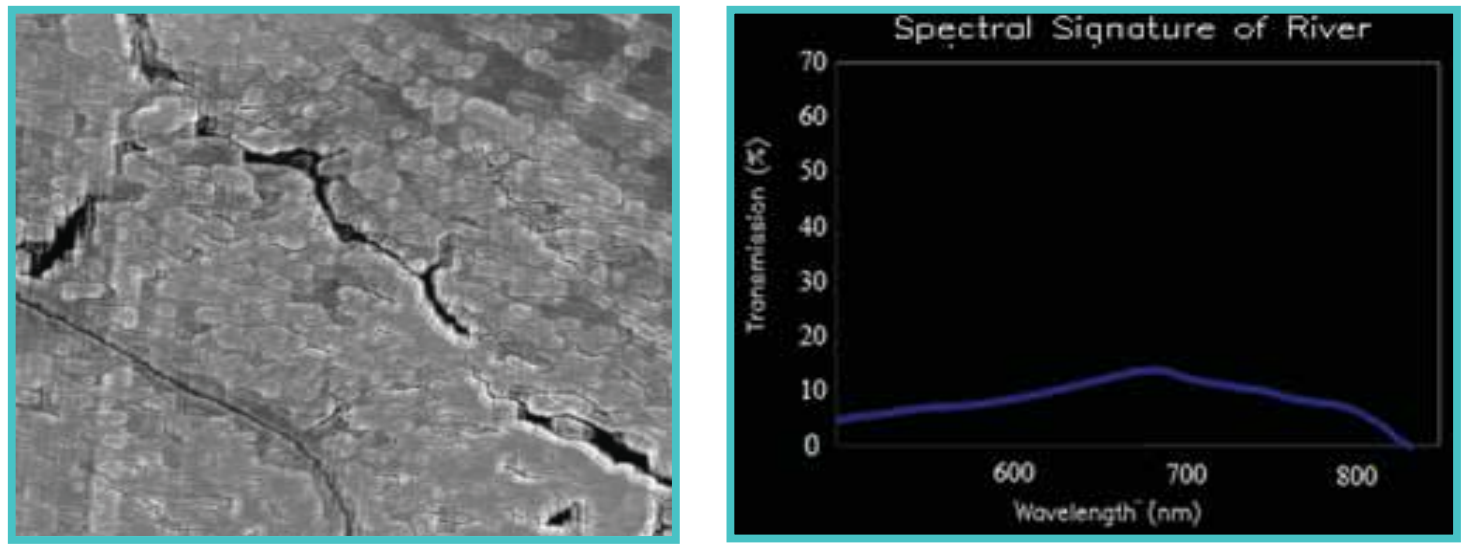

Figure 11. Image and spectral signature for river 

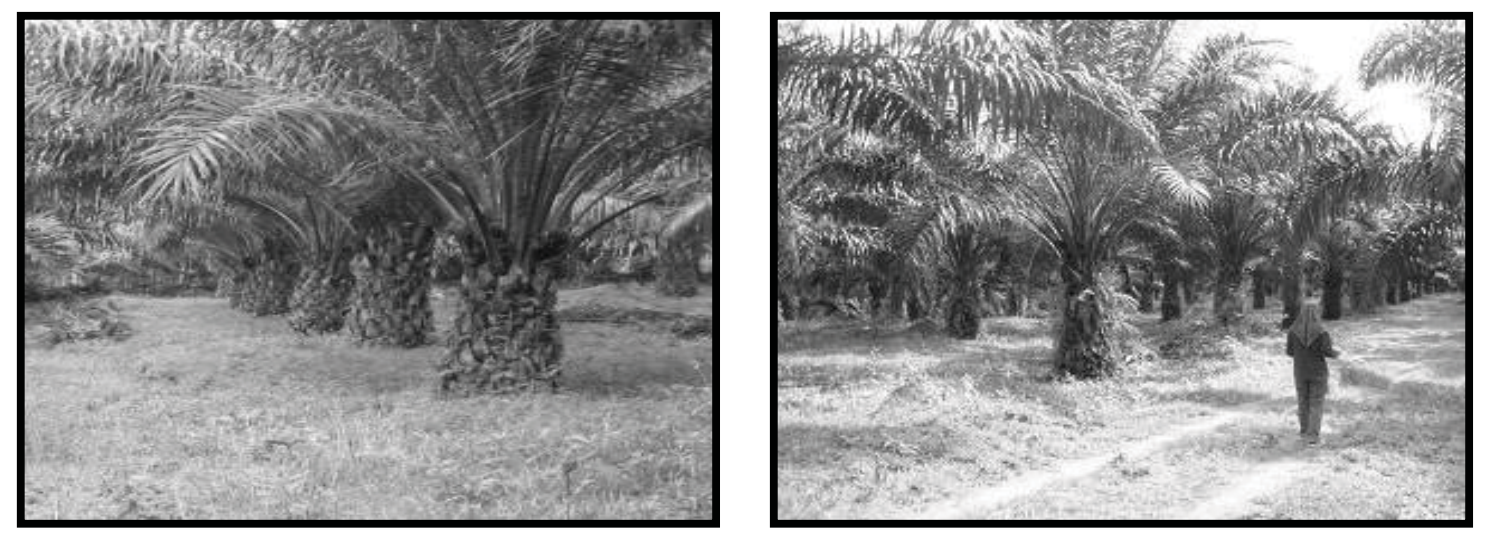

Figure 12. Ground photos for a young (L) and matured (R) oil palm plantations
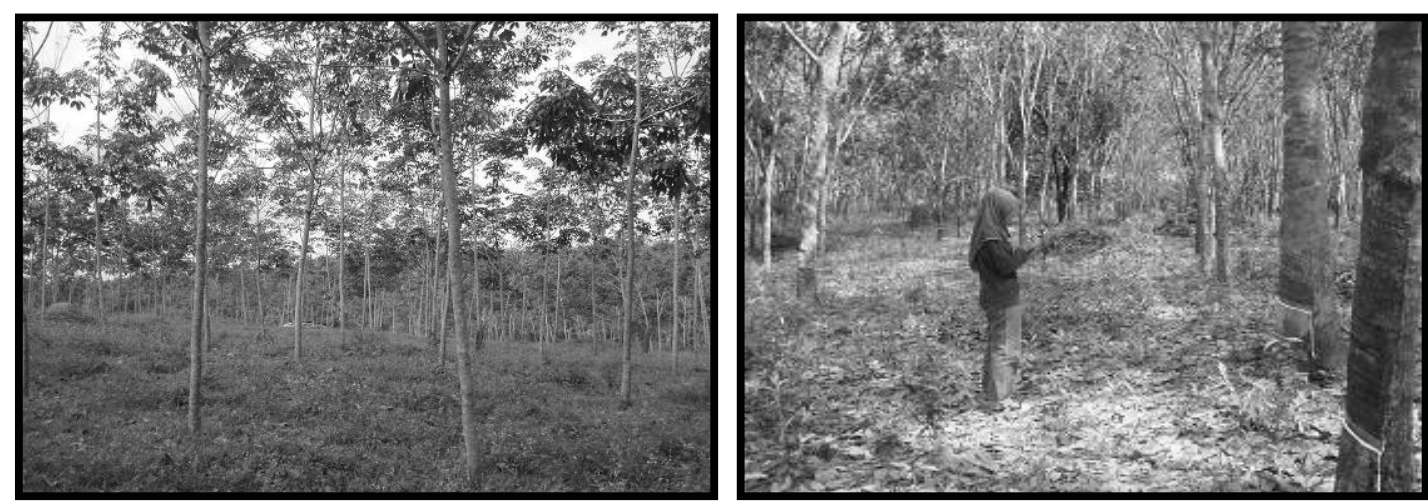

Figure 13. Ground photos for a young (L) and matured (R) rubber plantations
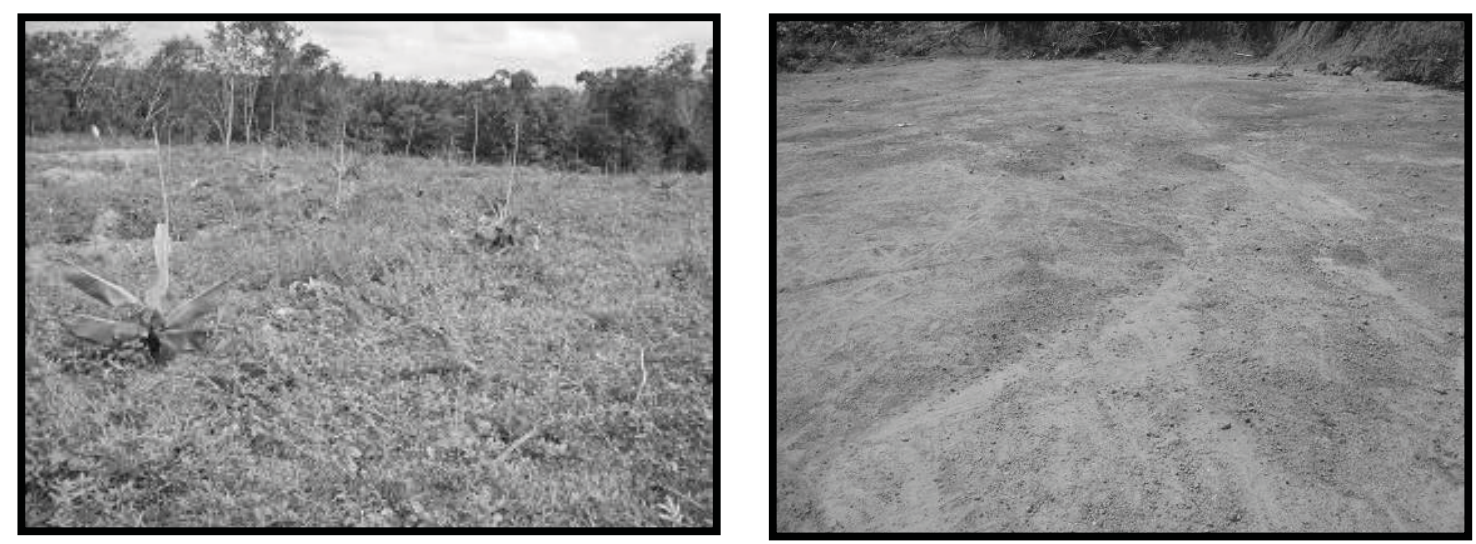

Figure 14. Ground photos for a mixed agriculture (L) and an open area (R) 

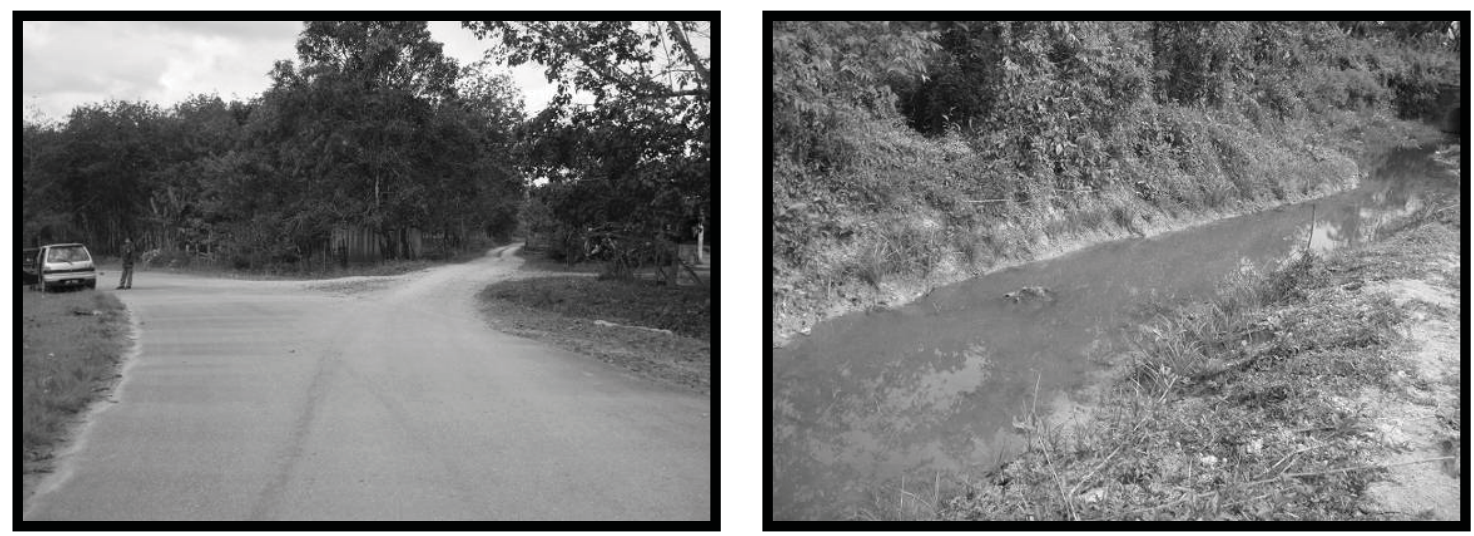

Figure 15. Ground photos for a road (L) and a small muddy river (R) 